\title{
INVESTIGATION OF PINE OIL METHYL ESTER BLENDS WITH DIESEL ON A COMPRESSION IGNITION ENGINE TO CONTROL OXIDES OF NITROGEN AND SOOT PARTICLES
}

\author{
M. Prabhahar ${ }^{1, *}$, S. Sendilvelan ${ }^{2}$, S. Prakash ${ }^{1}$ and M. Saravanakumar ${ }^{1}$ \\ 1,* Department of Mechanical Engineering, Aarupadai Veedu Institute of Technology, \\ Chennai-603104, (Tamilnadu) India \\ ${ }^{2}$ Department of Mechanical Engineering, Dr. M.G.R. Educational and Research Institute, \\ University, Chennai- 600095, (Tamilnadu) India \\ "E-mail: mprabhahar@avit.ac.in
}

\begin{abstract}
This paper presents the experimental investigation of palm oil produced by the transesterification process and glycerin as a by-product. Palm oil methyl ester blends with diesel blends were used in a compression ignition (diesel) engines to analyze the emission characteristics. Experimental results show that palm methyl ester blends meet the emission and performance requirements of a diesel engine. These blends provide less concentration of exhaust gas emissions. However, apart from its advantages, it produces low $\mathrm{HC}, \mathrm{CO}$ and higher $\mathrm{NO}_{\mathrm{x}}$ exhaust gas emissions as compared to diesel fuel. Thus, palm oil methyl ester can be considered as an alternative source of renewable energy to meet the energy demands of the future.

Keywords: Biodiesel, Palm oil methyl ester, Compression ignition engine, Direct-injection diesel engine.
\end{abstract}

๑ RASĀYAN. All rights reserved

\section{INTRODUCTION}

Biofuels considered as an alternative fuel for the fossil fuels which are depleting very fast and they create harmful environmental pollutions. The biofuels are usually considered recently are different types of biofuels are ethanol and biodiesel. ${ }^{1}$ Shehata et al. studied that by using corn and soybean blends with diesel fuel over a wide range of engine speeds, loads without modifying the engine parts. He concluded that the brake thermal efficiency for diesel, 20\% biofuels are inversely according to their viscosity or density and oxygen content and at the same time their arrangement in descending ordering regarding the heating values. ${ }^{2}$ Also concluded that the peak pressure of the cylinder for diesel fuel is higher than that for corn and soybean blended fuels with all engine conditions. Reducing the oxides of nitrogen and soot to meet the stringent emission standards received considerable attention in diesel combustion chemistry. ${ }^{3}$ Aqwu et al. experimentally concluded that the soybean biodiesel with diesel blends was found that by using soybean blended with petroleum diesel, the engine worked well. ${ }^{4}$ Lebeckas et al. used rapeseed oil in a diesel engine, the power output reduced and the brake specific fuel consumption increased. ${ }^{5}$ Sharon explained that using palm oil in a diesel engine produces best power output and minimum emissions and also with $25 \%$ diesel shows improved specific fuel consumption. ${ }^{6}$

Sharon et al. concluded that the performance, exhaust gas emission and heat emission, tests on indirect injection diesel engine with $10 \%$ volume of crude palm oil blended with diesel. The results showed lower engine performance and higher toxic-gas emissions when using the blended fuel. ${ }^{7}$ Canakci et al. reported the performance of diesel engine run with sunflower oil. Smoke emissions were reduced while brake specific fuel consumption increased as compared to the engine using pure diesel. ${ }^{8}$ Hassan concluded that the use of palm oil on diesel engine reduces the emissions. ${ }^{9}$

Fumigation is a process used to reduce engine emissions compared to normal operation. Methanol fuel has been used to reduce oxides of nitrogen, hydrocarbon and carbon monoxide ${ }^{10}$. The butanol diesel blends reduce the smoke density and nitrogen oxides from a diesel engine. The brake thermal efficiency decreases 
RASĀYAN J. Chem.

Vol. 10 | No. 4 |1075-1079 | October - December | 2017

with increase in butanol percentage in the blends. ${ }^{11}$ Sundarraj et al. studied that the influence of fumigation of air with methanol, methyl ethyl ketone, and liquefied petroleum gas and concluded that unburnt hydrocarbon and carbon monoxide emissions. ${ }^{12}$ An alternative for diesel fuel is named as biodiesel. It is produced by the chemical bonding of an alcohol with oils, fats, greases or chemically known alkyl esters. ${ }^{13}$ Sulphur content, flash point, and aromatic content are the favorable properties of diesel. ${ }^{14}$ Biodiesel is easy and simple to use in a diesel engine without modifications.

Oxygenated fuel has a chemical compound containing oxygen, it reduces the emission comes out from the engine. ${ }^{15,16}$ Biodiesel is an oxygenate, Sulphur-free and biodegradable fuel, and the oxygen helps improve its combustion efficiency, therefore, fewer greenhouse gases such as carbon dioxide are released into the atmosphere. ${ }^{17-19}$

\section{EXPERIMENTAL}

Transesterification process, the palm oil is used as a raw material to produce biodiesel. For a basic catalyst, either sodium hydroxide $(\mathrm{NaOH})$ or potassium hydroxide $(\mathrm{KOH})$ is generally used with methanol or ethanol. ${ }^{20}$ In this process, alkoxy is produced before the chemical reaction to improve efficiency as shown in Fig.-1.

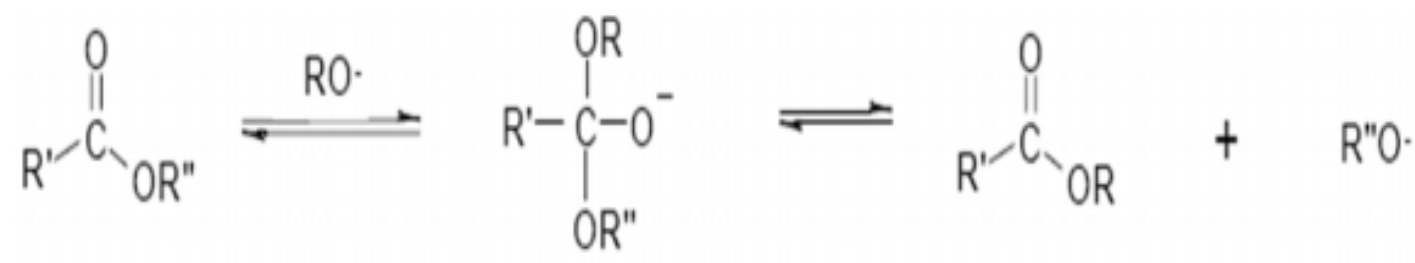

Fig.- 1: Mechanism of alkali alcoholysis ${ }^{21}$

To produce biodiesel, the alkaline catalyst is used with methanol by transesterification. The alcohol/catalyst mix is charged into a closed reaction vessel and the vegetable oil is added. ${ }^{22}$ The mixture is heated to the temperature of 50 to $60^{\circ} \mathrm{C}$ which is the boiling temperature of the alcohol. After agitation, the chemical reaction stopped and the mixture separates into an upper layer of methyl esters and a lower layer of glycerol diluted with un-reacted methanol. Two major products are produced: glycerin and biodiesel (methyl ester). The by-product glycerin contains unused catalyst and soaps. The crude glycerin is sent for storage. The methyl ester produced from the reaction is then washed with hot water and separated out by centrifugation. Blends of $20 \%$ palm oil esters are generally shown better efficiency without any major modification in the engine. The compression ratio effects have not been analyzed for the palm methyl ester - diesel blends. This palm oil methyl ester can be an alternate fuel for the conventional diesel fuel. Hence, the study of the palm oil methyl ester on a diesel engine for variable compression ratio is essential. In the present work, the effect of the compression ratio of palm oil methyl ester with diesel blended fuels on the performance and emission characteristic of fuel has been studied. The presence of oxygen in POME biodiesel which enhances the combustion as compared to diesel and biodiesel is more lubricant than diesel that provides additional lubrication. Palm oil biodiesel has higher viscosity, higher density, and lower calorific value than diesel.

Table-1: Properties of Palm Oil Methyl Ester and Diesel

\begin{tabular}{c|l|c|c|c}
\hline S. No. & \multicolumn{1}{|c|}{ Fuel Property } & Unit & Diesel & Palm Oil Methyl Esters \\
\hline 1 & Cetane Number & -- & 45 & 52 \\
\hline 2 & Specific Gravity $@ 15^{\circ} \mathrm{C}$ & $\mathrm{Kg} / \mathrm{m}^{3}$ & 830 & 872 \\
\hline 3 & Calorific Value & $\mathrm{MJ} / \mathrm{kg}$ & 42.5 & 38 \\
\hline 4 & Flash Point & ${ }^{\circ} \mathrm{C}$ & 49 & 132 \\
\hline 5 & Kinematic Viscosity $@ 40^{\circ} \mathrm{C}$ & $\mathrm{cSt}$ & 3.52 & 4.78 \\
\hline
\end{tabular}

*Data are given by supplier 


\section{RESULTS AND DISCUSSION}

The research engine test setup with the following configuration has been used for this work. Single cylinder, four strokes, Multifuel water cooled VCR engine. Stroke: $110 \mathrm{~mm}$, Bore: $87.5 \mathrm{~mm}$, Capacity 661 cc, Power $3.5 \mathrm{~kW}$, speed $1500 \mathrm{rpm}$, CR range 12:1-18:1. Eddy current dynamometer for loading.

Experiments were conducted at 17.5, 16.5 and 15.5 compression ratios with the selected engine loads varied from $0,3,6$ and $9 \mathrm{~kg}$. Before each measurement, the engine was warmed up and running steadily. The brake thermal efficiency, NOx, HC, $\mathrm{CO}$ emissions as well as the opacity are recorded and analyzed in this study. Variable compression ratio diesel engine, single cylinder CI engine was used to perform emission analysis. Figure-2 shows the variations of fuel consumption in $\mathrm{kg} / \mathrm{hr}$ versus loan in $\mathrm{kg}$. with varying compression ratio $15.5,16.5$ and 17.5. It can be observed that the fuel consumption is an indication of the efficiency with which the power developed by the engine defined. It is found that higher compression ratio of 17.5 gives better fuel consumption than the other two.

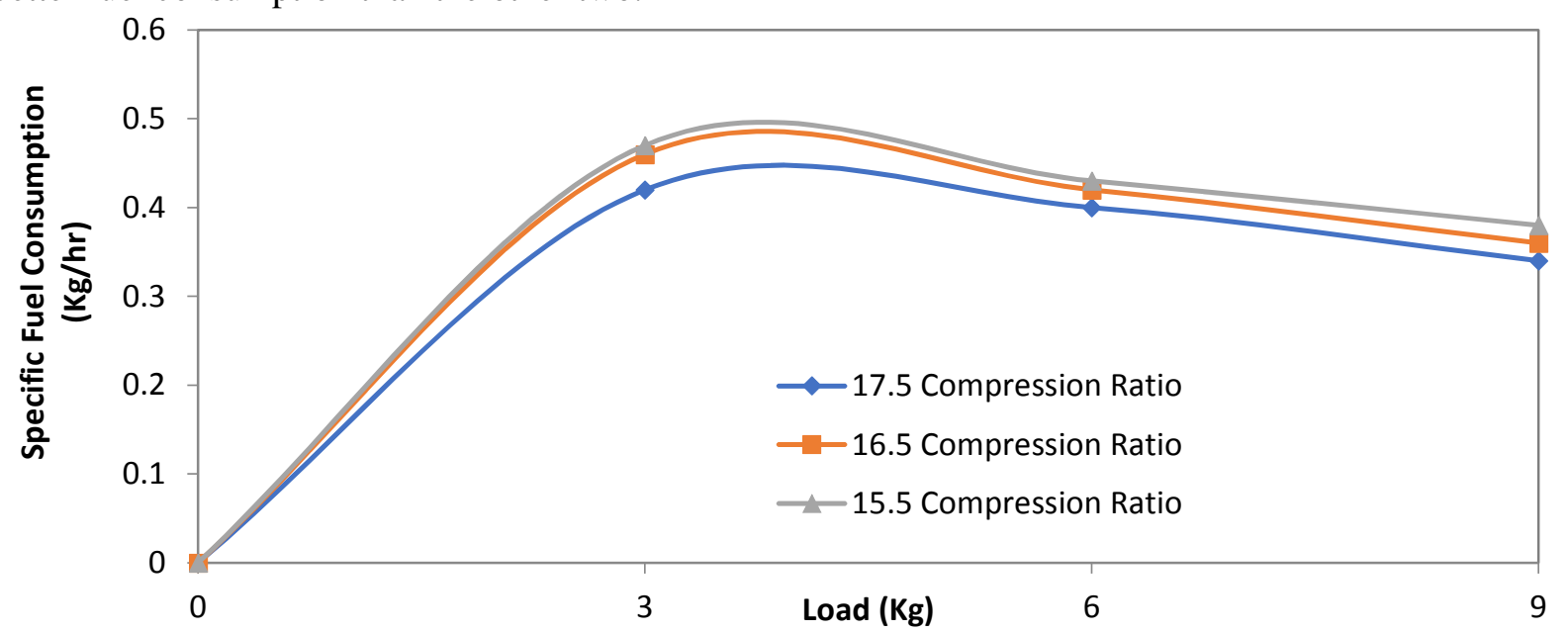

Fig.- 2: Variation of specific fuel consumption in $\mathrm{kg} / \mathrm{hr}$. versus load in $\mathrm{kg}$

Figure- 3 shows the variation of carbon monoxide with three different compression ratios. The higher compression ratio increases better combustion which reduced the carbon monoxide in \% by volume. Carbon monoxide (CO) gas is toxic products produced from all hydrocarbon combustion which can be reduced by higher oxygenated nature of fuel include biodiesel. Complete oxidation of the fuel produces a complete combustion and contributes to the lower emission of carbon monoxide (CO).

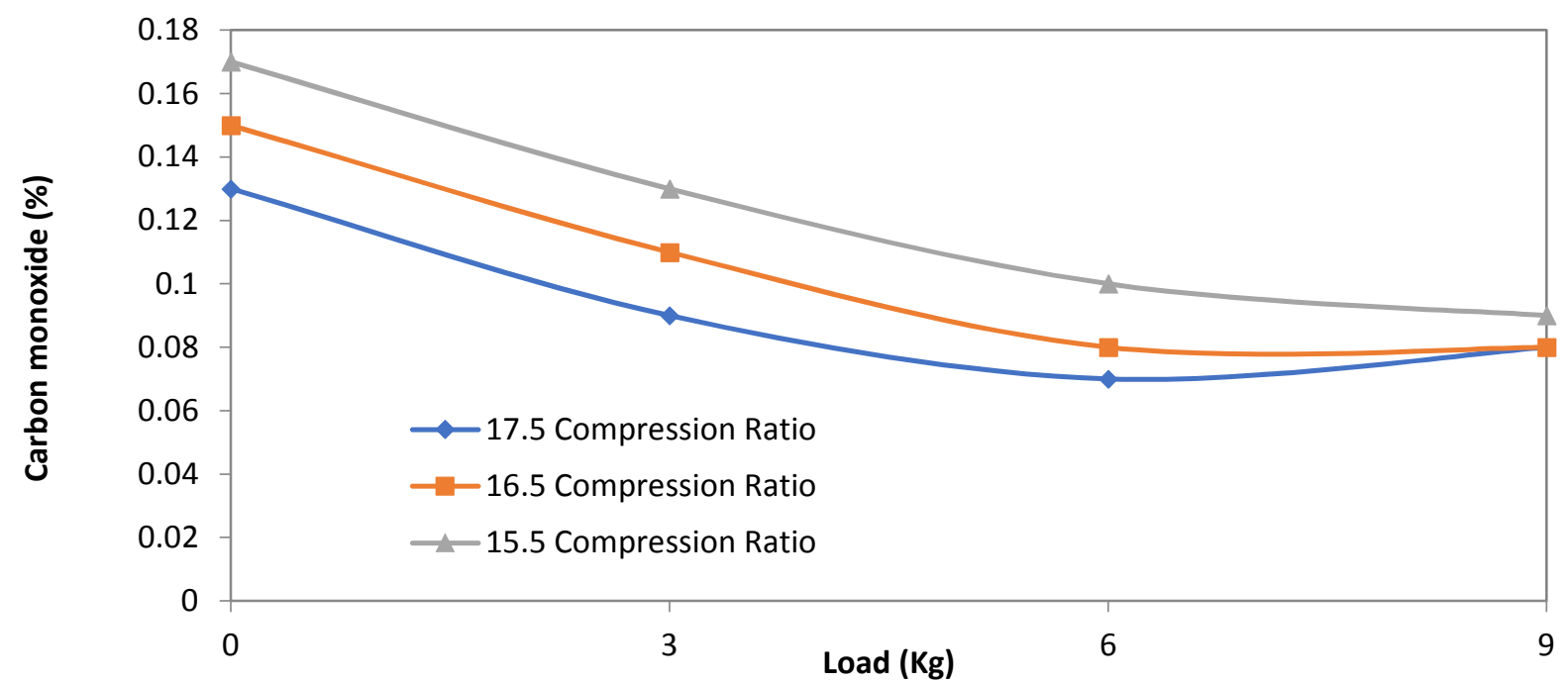

Fig.- 3: Variation of Carbon monoxide in \% by vol. versus load in $\mathrm{kg}$ 
Figure-4 and 5 show the variation of hydrocarbon and oxides of nitrogen in ppm versus load. The hydrocarbon in $\mathrm{ppm}$ reduces with 17.5 compression ratio. But the compression ratio reduces the value of hydrocarbon increases considerable at all loads. Hydrocarbon emissions also tend to be reduced when high cetane fuels are combusted. The cetane number for palm oil methyl ester is 52 compared with 45 cetane number for the diesel fuel as shown in Table-1. Experiments with biodiesel found that a higher proportion of biodiesel attributes to increasing in NOx emission due to higher oxygenated nature content in biodiesel fuel.

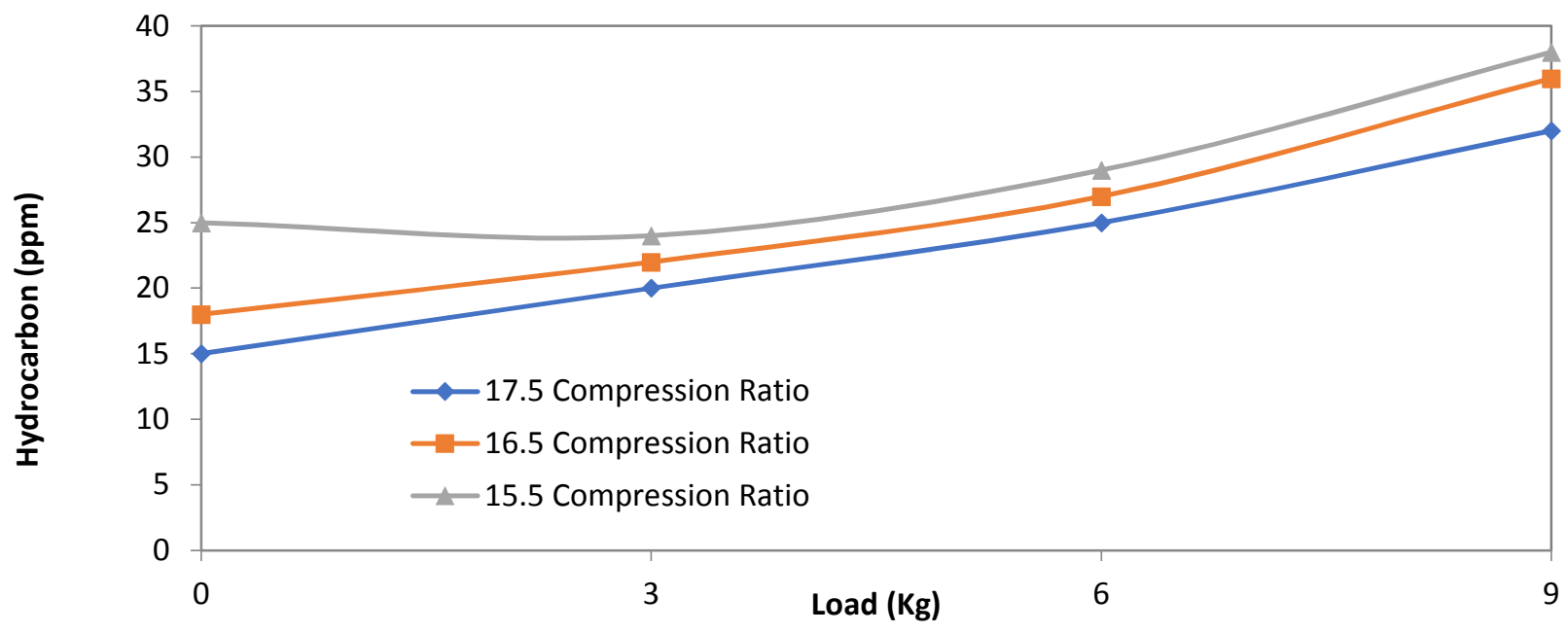

Fig.- 4: Variation of Hydrocarbon in ppm versus load in $\mathrm{kg}$

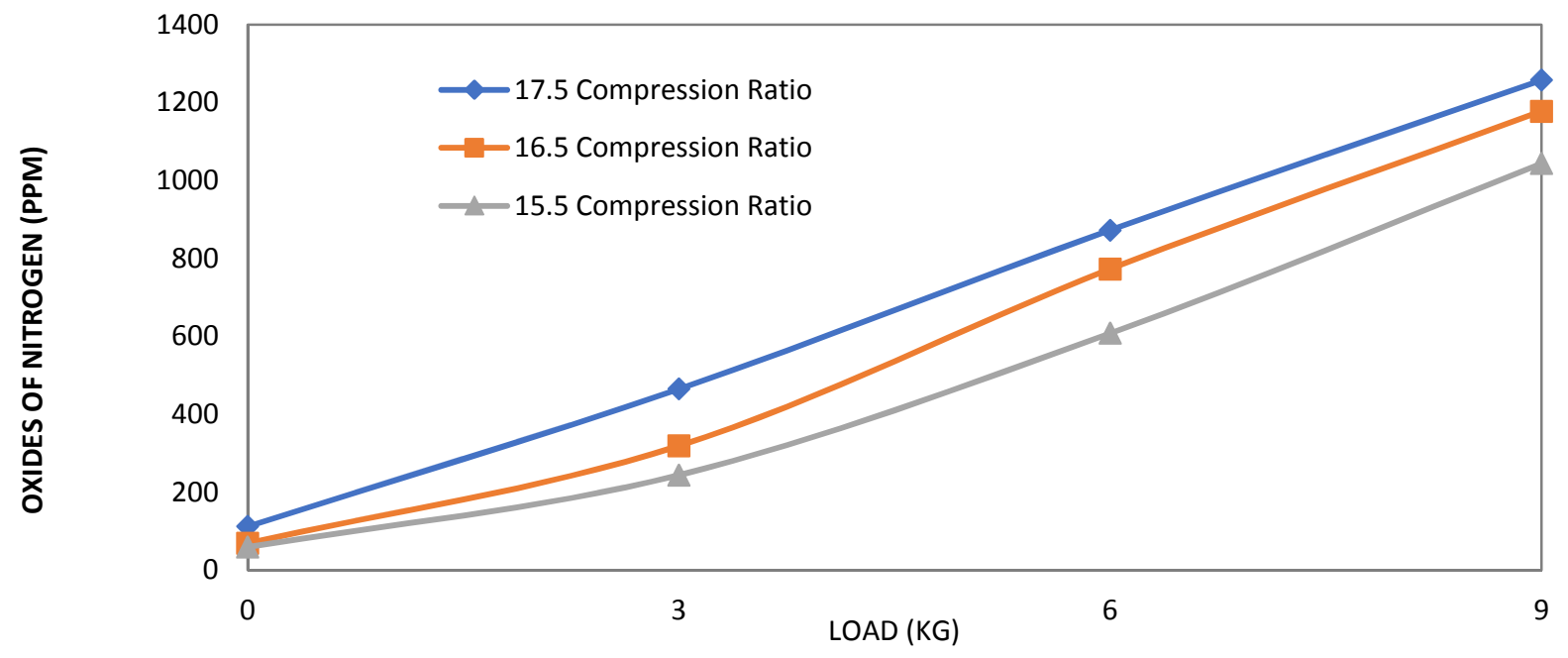

Fig.- 5: Variation of Oxides of Nitrogen in ppm versus load in $\mathrm{kg}$

The chemical nature of the fuel which contains a high level of oxygen and the absence of the aromatic molecules in the fuel composition has reduced the formation of the soot particles with the increase in oxidation rate, which in tune reduce the opacity percentage. With a higher compression ratio of 17.5 , the opacity is marginally reduced for all loads as shown in Fig.-6.

\section{CONCLUSION}

The aim of the investigation was successfully carried out and the following conclusions were drawn: Biodiesel produced from Palm Oil Methyl Ester (POME) can be successfully used as alternative fuels in existing diesel engines without any major modifications. Better fuel economy was observed at 17.5 
compression ratio compared to other compression ratios. It is concluded that the blends of POME as an alternative fuel in a variable compression ratio engine shows the optimum performance and emission characteristics.

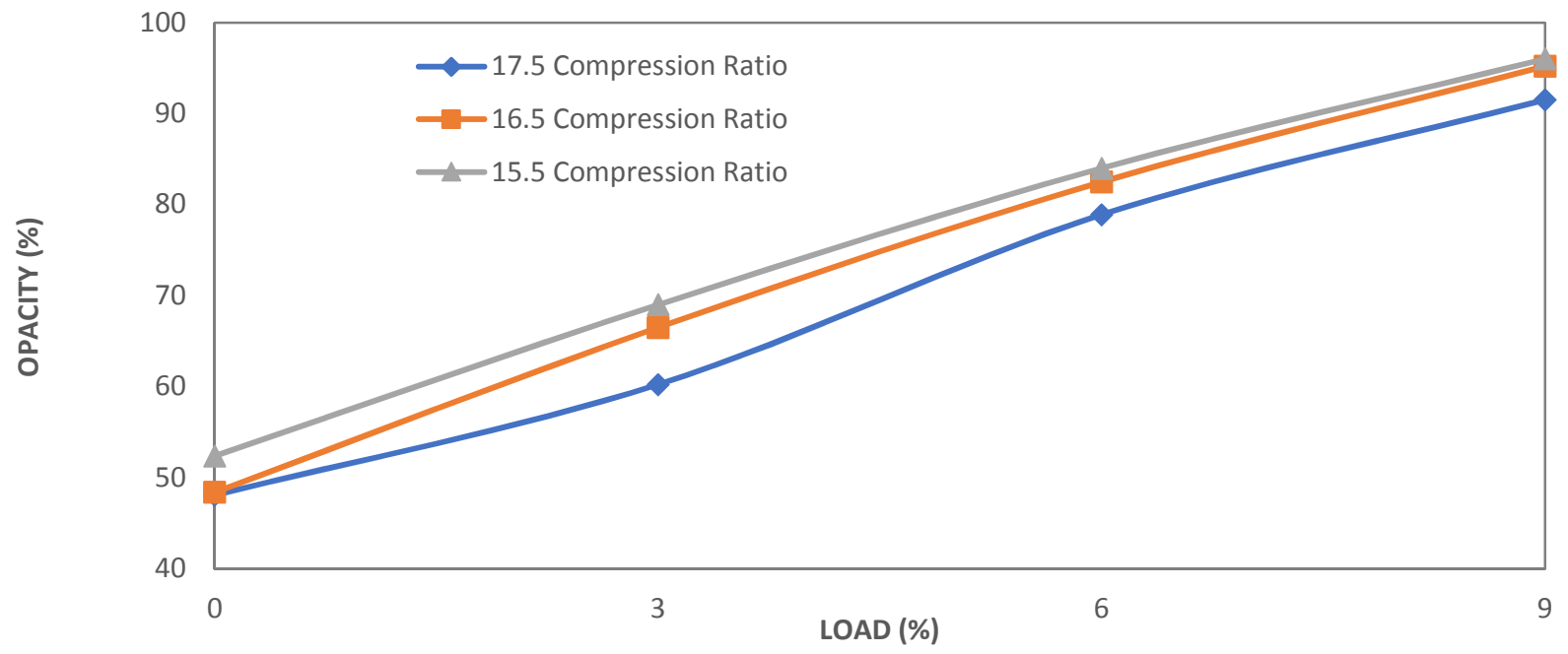

Fig.- 6: Variation of Opacity in \% versus load in $\mathrm{kg}$

\section{REFERENCES}

1. C.S. Duke, R.V. Pouyat, G.P. Robertson, W.J. Parton, J. Issues In Ecology, 17, 1(2013)

2. M.S. Shehata, A.M.A. Attia, S.M. Abdel Razek, Fuel, 161, 49(2015)

3. S. Sendilvelan, K. Bhaskar, Rasayan Journal of Chemistry, 9 (4), 692(2016)

4. O.E. Aqwu, A.N. Okon, F.D. Udoh, Journal Petroleum Engineering, 1(2015)

5. G. Labeckas, S. Slavinskas, Energy Conversion Management, 47 (13-14), 1954(2006)

6. H. Sharon, K. Karuppasamy, D.R. Soban Kumar, A. Sundaresan, Renewable Energy, 47, 160(2012)

7. H. Sharon, P. Jai Shiva Ram, K. Jenis Fernando, S. Murali, R. Muthusamy, Energy Conversion Management, 73, 95(2013)

8. M. Canakci, A.N. Ozsezen, A. Turkcan, Biomass and Bioenergy, 33 (5), 760(2009)

9. M.N.A. Hassan, P. Jaramillo, W.M. Griffin, Energy Policy, 39 (5), 2615(2011)

10. S. Sendilvelan, K. Bhaskar, Rasayan Journal of Chemistry, 10 (1), 111(2017)

11. S. Sendilvelan, K. Rajan, Rasayan Journal of Chemistry, 10 (1), 190(2017)

12. C. Sundar Raj, S. Arul, S. Sendilvelan, C.G. Saravanan, Energy Sources, Part A, Recovery Utilization, and Environmental Effects, 32 (17), 1603(2010)

13. A. Demirbas, Energy Conversion Management, 49 (1), 125(2008)

14. B.R. Moser, A. Williams, M.J. Haas, R.L. McCormick, Fuel Processing Technology, 90(9), 1122(2009)

15. S. Sendilvelan, K. Bhaskar, Rasayan Journal of Chemistry, 10 (3), 844(2017)

16. L. Sassykova, Sh. Gil'Mundinov, A. Nalibayeva, I. Bogdanova, Revue Roumaina de Chimie, 62 (2), 107(2017)

17. D.A. Baiseitov, M.I. Tulepov, L.R. Sassykova, Sh.E. Gabdrashova, E. Gul'dana, D.A.Zhumabai, K.K. Kudaibergenov, Z.A. Mansurov, International Journal of Chemical Science, 13 (2), 1027(2015)

18. L. R. Sassykova, A. Ussenov, A. T. Massenova, Sh. A. Gil' mundinov, K. S.Radhmetova, V. N. Bunin, Zh. T. Basheva, M. K. Kalykberdiyev, International Journal of Chemical Science, 14 (1), 206(2016)

19. P.T. Vasudevan, M. Briggs, Journal of Industrial Microbiology Biotechnology, 35 (5), 421(2008)

20. N. Yilmaz, T.M. Sanchez, Energy, 46 (1), 126(2012)

21. K. Khalid, K. Khalid, American Journal Applied Sciences, 8 (8), 804(2011)

22. S. Nallusamy, S. Sendilvelan, K. Bhaskar, N.M. Prabu, Rasayan Journal Chemistry, 10(3),873(2017)

[RJC-1847/2017] 